\title{
O Colonial Tardio e a Economia do Rio de Janeiro na Segunda Metade dos Setecentos: 1750-90^
}

\author{
Fábio Pesavento \\ Coordenador do Núcleo de Economia Empresarial (ESPM-SUL) \\ Endereço para contato: Rua Guilherme Schell, 350 - Santana - Porto Alegre - RS \\ CEP: $90640-040$. \\ E-mail: fpesavento@espm.br
}

Recebido em 04 de janeiro de 2011. Aceito em 11 de abril de 2012.

\begin{abstract}
Resumo
Um ponto importante na historiografia brasileira é o debate sobre o colonial tardio. A ideia sugerida por Dauril Alden é a de que a Colônia iria presenciar uma profunda crise econômica após a queda da extração aurífera na região mineira. Neste cenário, a economia colonial presenciou um retorno às atividades rurais (agricultura). Com dados levantados a partir de 1790, João Fragoso contrapõe a ideia de colonial tardio, para a economia do Rio de Janeiro, ao sugerir a formação de uma vasta rede de abastecimento, apontando não uma crise, mas a formação de um amplo mercado interno especialmente na região sudeste. Mas qual seriam os resultados para o período 1750-90, justamente quando a queda da extração do ouro se intensifica? A fim de colher novos subsídios para o debate trabalharam-se com 6.500 escrituras públicas depositadas no Arquivo Nacional, além de outras fontes primárias que envolviam a economia do termo da cidade do Rio de Janeiro entre 1750-90. Os resultados apontam para um revigoramento do setor rural e uma estagnação da atividade econômica do Rio de Janeiro no mesmo período, e não uma crise.
\end{abstract}

\section{Palavras-Chave}

Rio de Janeiro, colonial tardio, escrituras, mercado interno, crise econômica

\begin{abstract}
An important point in Brazilian history is the debate on late colonial. The idea suggested by Dauril Alden is that the colony would witness a profound economic crisis after the decrease of gold extracting. In this scenario, the colonial economy witnessed a return to rural activities (agriculture). With data collected from 1790, João Fragoso opposes the idea of late colonial suggesting the formation of a broad distribution network, showing not a crisis, but the formation of a broad domestic market. Moreover, Fragoso shows that business is linked to rural losing importance since 1790 . However what would the results for the period 1750-90, just when the decrease of gold extraction intensifies, be? In order to reap further benefits for the late colonial debate. Up to 6500 deed deposited in the National Archives have been worked up, including and other

\footnotetext{
- Versão do artigo apresentado no XXXVII Encontro Nacional de Economia - ANPEC 2009. Agradeço aos comentários dos avaliadores anônimos e dos monitores de pesquisa da ESPMSUL (Luisa Dalla Valle Geisler e Marcelle Moreira Pujol). Erros e omissões remanescentes são de inteira responsabilidade do autor.
} 
primary sources that the term involving the economy of Rio de Janeiro. The results point to a reinvigoration of the rural sector and a stagnation of economic activity in Rio de Janeiro in the same period and no crisis.

\section{Keywords}

Rio de Janeiro, late colonial, deeds, internal market, economic crisis

\section{JEL Classification}

N26, N36

\section{Introdução}

Desde antes de 1750, o porto carioca já se destacava nos quadros do império ultramarino português. ${ }^{1}$ A origem desse processo, em boa medida, remonta à expansão da região mineira com a descoberta do ouro na virada do século XVII para o XVIII. O ouro gerou um aumento no fluxo de bens e serviços para a região mineira, o qual intensificou o comércio de abastecimento, levando ao estabelecimento de uma série de redes comerciais. ${ }^{2}$ Portanto, na segunda metade do XVIII, tornam-se nítidas as consequências desse processo, qual seja, o espaço fluminense transforma-se num dos principais locus da dinâmica econômica colonial brasileira.

Se a extração aurífera aumentou o fluxo de mercadorias, agentes, informações e crédito para a região sudeste, quais os seus efeitos quando do seu declínio? Um importante debate historiográfico se descortina para responder essa indagação. De um lado, Dauril Alden sugere que a Colônia vai presenciar uma profunda crise econômica, e que os recursos existentes foram deslocados para o setor agrícola (subsistência ou voltados para o mercado externo). A partir de uma ampla pesquisa documental pós 1790, João Fragoso aponta para a formação de uma vasta rede de abastecimento interligando diversas partes da região sudeste, sugerindo não uma crise, mas a formação de um amplo mercado interno.

A fim de colher novos subsídios para o debate e visualizar o impacto da crise aurífera sobre a economia carioca, trabalharam-se com 6.500 escrituras públicas depositadas no Arquivo Nacional, além de outras fontes primárias que envolviam a economia do termo da cidade do

Ver Sampaio (2003).

2 Sobre o comércio do abastecimento cf. Zemella (1990); Chaves (1999); Carrara (2007). 
Rio de Janeiro. ${ }^{3}$ Com isso, construiu-se um painel de indicadores econômicos que permitem analisar o nível de atividade econômica fluminense entre 1750-90, período no qual se verifica a queda na intensidade da extração mineira.

O trabalho foi dividido em quatro partes, além desta introdução. Inicia-se com um breve resumo da economia do Rio de Janeiro na segunda metade dos setecentos, assim como um panorama do debate acerca a crise aurífera. Em seguida, apresentam-se os dados sobre o comportamento da economia carioca entre 1750 e 1790, passando para a análise cliométrica dos dados encontrados.

\section{O Rio de Janeiro depois da Queda da Produção Aurífera e o Colonial Tardio}

Nesta primeira parte do trabalho apresenta-se uma brevíssima contextualização do período e da economia fluminense na segunda metade dos setecentos. Além disso, realiza-se uma revisão do debate sobre a crise aurífera mineira e seus impactos sobre a economia colonial.

Quando o rush mineiro inicia, na virada do século XVII para o XVIII, o Rio de Janeiro ainda é um porto, mas cada vez mais a economia fluminense se desloca para o interior do Brasil. A notícia da existência das jazidas provocou uma admirável migração para Minas Gerais. Indivíduos de diversas classes sociais, de todas as partes do Reino e da Colônia, partem para a região mineira, o que acarreta um aumento populacional sem precedentes. Isso desencadeou não só o aumento do consumo, mas a formação de novos povoados, vilas e cidades, elevando a circulação e produção de diversas mercadorias. Além disso, torna-se necessário montar um aparato administrativo e fiscal para garantir a porção da Coroa, reforçando a expansão e importância da região sudeste brasileira.

\footnotetext{
3 "Termo é originário do grego terma, exprimindo o sentido de marco, mourão, com que se demarcam as terras. E daí, extensivamente, a significação de extremidade, limite ou fim" (Silva, 1998, p.805). No presente trabalho inclui a "região central" da cidade do Rio de Janeiro além das freguesias de Santa Cruz, Campo Grande, Guaratiba, Jacarepaguá, Gávea, Engenho Velho e Novo, Inhaúma, Irajá, Ilha do Governador, Baía de Guanabara, Ilha de Paquetá, São Cristóvão, Santana, Santa Rita, Candelária, São José, Sacramento, Glória e Espírito Santo (Noronha Santos, 1965).
} 
Este período também vai presenciar o crescimento do comércio de cabotagem entre diferentes partes da colônia, reforçando a incipiente interligação econômica entre sul, sudeste e nordeste. Um exemplo do crescimento da movimentação do porto do Rio de Janeiro no início do século XVIII é arrecadação da dízima da alfândega. Por exemplo, no triênio iniciado em 1712, a arrecadação chegou a 53:200\$000 réis e no período 1724-26, chegou a 97:400\$000 réis (Carrara, 2008: 19). O papel do caminho novo também deve ser destacado, pois permitiu uma via de comunicação mais rápida, de 12 a 15 dias, do Rio com a região aurífera.

Na virada da metade do século XVIII verifica-se uma intensificação do fluxo de pessoas, navios e comércio, ampliando a importância política do espaço fluminense no império português. Isso se põe a descoberto em 1763, quando é transferida a capital de Salvador para o Rio. Outro exemplo é o tribunal da Relação do Rio de Janeiro, criado já em 1750 para resolver pendências jurídicas ocorridas no sul, centro-oeste e sudeste do país. Com isso, houve a migração de juristas, da alta nobreza e da burocracia portuguesa, além de um maior contingente de militares (Cavalcanti, 2004).

Um personagem de destaque no século XVIII foi Sebastião José de Carvalho e Melo, o Marquês de Pombal. ${ }^{4}$ Durante o período pombalino (1750-77), percebe-se uma mudança nas diretrizes do Estado português. Em linhas gerais, Pombal arrefece a influência política da Igreja e da nobreza no Estado, além de incorporar parte da burguesia nascente (concedendo-lhe privilégios) e de buscar políticas econômicas que permitissem diminuir a dependência inglesa (econômica e política).

Esse quadro parece claro quando se observam os desdobramentos de seu governo, durante os anos 1750 . Com relação ao Brasil, pode-se dizer, de uma maneira geral, que as primeiras ações de Pombal são no sentido de reorganizar a administração (política) e a economia, uma vez que o Império passava por dificuldades financeiras em face da queda da extração aurífera na região das gerais e o arrefecimento das exportações brasileiras.

4 Sobre o Marquês de Pombal destaca-se Falcon (1982); (2005), Azevedo (2004), Maxwell (1996). 
Se antes da administração de Marquês de Pombal a igreja e os ingleses exerciam influência nos desígnios portugueses, após a morte de dom João $\mathrm{V}$ esses setores vão ter seus prestígios reduzidos. A ação de governo posta em prática por Carvalho e Melo representa uma nova "ideologia" (regra informal) no Estado, a qual gera novas regras formais (leis e decretos). Esse movimento altera o ambiente institucional e afeta o desempenho econômico não apenas do Reino, mas também do seu principal porto, o Rio de Janeiro (Pesavento, 2009). Nesse sentido, parece nítido que existiu uma alteração do ambiente institucional luso-brasileiro.

Este período também vai presenciar a implementação de novas culturas no Rio de Janeiro, ${ }^{5}$ como o anil, o arroz, a cochonilha, o linho cânhamo, a amoreira (bicho de seda) e o café. Na verdade, a introdução de medidas de fomento a diversificação agrícola estão inseridas num contexto peculiar. De um lado, existe o crescimento da demanda inglesa por matérias-primas, fruto da Revolução Industrial. De outro, as medidas pombalinas de fomento agrícola. Portanto, a segunda metade do século XVIII vai presenciar a consolidação não só da economia, como também da estrutura política fluminense, ao lado do crescimento de novas culturas.

Ainda resta uma questão: passado o "ciclo do ouro" quais os seus efeitos sobre a economia do Rio de Janeiro? Se a extração aurífera aumentou o fluxo de mercadorias, agentes, informações, crédito na região sudeste, quais os seus efeitos quando do seu declínio? Um importante debate historiográfico se descortina para responder a indagação. De um lado, existe o argumento - apresentado por Celso Furtado em Formação Econômica do Brasil - de que após o arrefecimento da extração aurífera a economia colonial brasileira passou por um processo de atrofiamento.

A explicação reside no fato de que a renda entra em declínio, uma vez que boa parte dos agentes regrediu para um regime de subsistência. Ela é seguida por boa parte da historiografia brasileira, ganhando revigoramento com o trabalho de Dauril Alden, o qual sugere que a Colônia vai presenciar uma forte crise econômica após o arrefecimento da extração aurífera.

\footnotetext{
5 Prado Júnior (2006) destaca a diversificação da agricultura em diferentes regiões do Brasil. Sobre a diversificação agrícola no Rio de Janeiro durante o XVIII ver Alden (1999), Cavalcanti (2004) e Pesavento (2009).
} 
"A principal causa da crise foi a queda vertiginosa na renda, tanto pública quanto privada, do Brasil iniciada no começa da década de 1760. A principal causa do severo corte na renda da coroa proveniente do Brasil foi o declínio da produção das minas de ouro e diamantes do interior." (ALDEN, 1999: 549)

Em função disso, os agentes deslocam seus recursos para o setor agrícola, em especial para a subsistência. Esse processo Caio Prado Júnior chamou de renascimento agrícola. ${ }^{6}$ Para Alden, o colonial tardio passa pelo boom do ouro, seguido da queda da extração e em seguida pelo revigoramento "da forma tradicional da riqueza colonial, a agricultura de exportação" (Fragoso \& Florentino, 2001: 84).

O livro Arcaísmo como Projeto, de João Fragoso e Manolo Florentino, síntese das teses de doutorado dos autores, acabou apresentando uma inovação no que diz respeito a esse debate. A ideia central da referida obra é a existência de um mercado interno colonial "a estrutura de produção colonial gera os seus mercados de homens e alimentos, o que, por sua vez, viabiliza a aparição de circuitos internos de acumulação para além das trocas com a Europa" (Fragoso \& Florentino, 2001: 19). João Fragoso e Manolo Florentino também destacam uma nova interpretação sobre o declínio aurífero:

"uma época marcada não tanto por uma recuperação econômica, mas principalmente um período de consolidação de novas formas de acumulação do Sudeste-Sul escravista, formas essas coincidentes com o domínio do capital mercantil e, pois, com a hegemonia de uma nova elite econômica. A elite, nesse caso, seria constituida pela comunidade de comerciantes de grosso trato residentes na praça mercantil do Rio de Janeiro. (Fragoso \& Florentino, 2001:84-5)."

${ }^{6}$ Avaliador anônimo atentou para um importante aspecto, qual seja, que o conceito de crise do colonial tardio é distinto de renascimento agrícola, podendo os dois coexistir de forma relacionada em momentos distintos. 
Por esse ponto de vista, a economia do Rio de Janeiro não atravessaria um renascimento agrícola, muito menos uma crise pós "ciclo do ouro", uma vez que a produção carioca já estava voltada para atender o mercado interno. Esse trabalho teve segmento para outros períodos e regiões, como, por exemplo, as teses de doutoramento de Júnia Furtado e de Antônio Carlos Jucá de Sampaio.

Há uma série de outras contribuições que não poderão ser tratadas aqui, mas que merecem menção por se colocarem nos interstícios desse debate. Citam-se os trabalhos de Charles Boxer, John Monteiro, Kenneth Maxwell, Stuart Schwartz, Larissa Brown e Rae Flory. Além disso, o início do século XXI testemunhou uma série de novos trabalhos, ${ }^{7}$ que lançaram mão de ampla pesquisa documental, além de diluir seu campo de análise, incorporando muito dos chamados aspectos "extraeconômicos". Importante destacar que são estudos que não têm a preocupação de analisar "as linhas gerais" da economia brasileira, mas sim de estudar os pormenores de uma região específica do Brasil ou da América Portuguesa, o que, por vezes, contrapõe as interpretações tradicionais da história econômica brasileira.

Em resumo, dentro do debate historiográfico sobre o tema aqui tratado, Alden (1999) afirma que a economia do Rio de Janeiro pós 1750 (especialmente durante a década de 1760) estaria assolada por uma perda de ritmo, na medida em que a atividade mineradora foi arrefecida, enfraquecendo os fluxos monetários e a capacidade de realizar inversões. Diante desse cenário, os agentes regressaram para a produção agrícola (subsistência ou de exportação). Esse processo foi denominado renascimento agrícola ou, para alguns autores, de colonial tardio. Com base em ampla documentação primária pós 1790, Fragoso (1998) aponta que a economia carioca não presenciou o renascimento agrícola, pois a produção agrícola carioca estava voltada para o mercado interno de abastecimento, desde antes do declínio mineiro. Uma vez realizado um breve panorama da atividade econômica do Rio de Janeiro e visto o diálogo no que diz respeito à revisão historiográfica, parte-se para a incorporação de novos subsídios ao debate.

Fragoso (2006) e (2007); Furtado (2001). 


\section{A Economia do Rio de Janeiro e a Crise Aurífera: Novos Sub- sídios para a Análise}

Nesta parte do trabalho, com base em ampla pesquisa documental primária, busca-se incorporar novos subsídios ao debate. Cabe a ressalva de que o presente estudo depara-se com a imprecisão das informações primárias do período analisado, o que prejudica a construção dos argumentos, deixando espaço para interpretações não conclusivas. Além disto, soma-se o fato da influência do jugo político nas relações sociais, o qual encobre as relações formais pelo véu da informalidade, abrindo espaço para o comportamento oportunista por parte dos agentes envolvidos nas transações. Assim, por vezes, o preço não é resultado do comportamento da oferta e da demanda, mas sim do ambiente institucional, que pode variar de freguesia para freguesia, pois é resultado das relações sociais, construídas com o passar dos anos.

Apesar do Rio de Janeiro figurar em inúmeros estudos sobre a sua estrutura socioeconômica, existe uma limitação: o diminuto número de pesquisas quando se utiliza o recorte $1750-90$. Isso pode ser explicado em função dos resultados encontrados por Sampaio (2003), quais sejam, de que o mercado interno, especialmente depois da década de 1740, já desempenhava um papel importante na dinâmica econômica fluminense. Imagina-se que o resultado manter-se-ia entre 1750-90, uma vez que Fragoso (1998) também mostrou o forte desenvolvimento das atividades ligadas ao mercado interno no Rio de Janeiro depois de 1790.

Contudo, a análise realizada por Pesavento (2009) mostrou um comportamento que revela novos subsídios para a compreensão da economia do Rio de Janeiro na segunda metade do século XVIII. Entre eles, um comportamento altista dos bens rurais frente aos urbanos na década de 1760-70 (conforme aponta o Gráfico 2). Diante desse resultado, buscam-se novos subsídios para verificar:

a. até que ponto houve crise pós 1750;

b. se ocorreu um renascimento agrícola.

Ao total, foram digitalizadas mais de 6.500 escrituras públicas no Arquivo Nacional envolvendo o termo da cidade do Rio de Janeiro. ${ }^{8}$

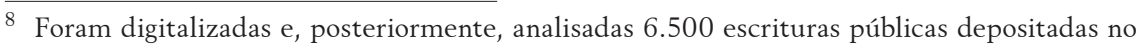


Dessas, 5.329 puderam ser analisadas e 2.503 tiveram seus valores reconhecidos. Convém esclarecer que a classificação das escrituras públicas seguiu estudos anteriores (Sampaio, 2003; Fragoso, 1998). Portanto, foram classificadas da seguinte maneira e distribuídas (por valor e número) conforme o Gráfico 1 abaixo.

a. urbanas: irá compreender aquelas escrituras de prédios urbanos (sobrados, moradas de casas térreas, sobradinhos, chãos, lojas, bancas e etc);

b. rurais: escrituras de compra e venda de terras, engenhos, sítios e fazendas;

c. empréstimos: escrituras de dinheiro a razão de juros, dívida e obrigação;

d. chácaras: escrituras de compra e venda de chácaras;

e. embarcações: transações que envolvem corvetas, saveiros e demais embarcações;

f. sociedades: escrituras de associação para fins mercantis.

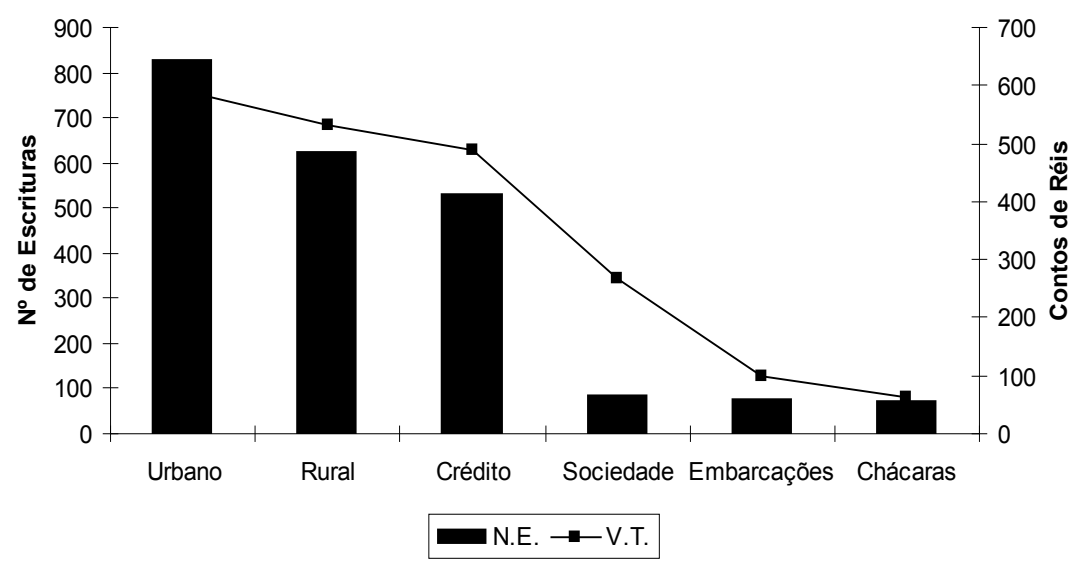

Gráfico 1 - Número e valor total das escrituras por categoria: 1750-90

Fonte: AN, escrituras públicas depositadas no $1^{\circ}, 2^{\circ}$ e $4^{\circ}$ Ofício de Notas. Elaboração própria.

NE: número de escrituras, VT: valor total $=$ soma total do valor de 2.503 escrituras com valores reconhecidos.

$1^{\circ}, 2^{\circ}$ e $4^{\circ}$ Ofício de Notas do Arquivo Nacional. O $3^{\circ}$ Ofício de Notas, no qual predominam procurações, estava interditado por ocasião da pesquisa. 
O gráfico acima mostra que as escrituras urbanas são predominantes em número e em valor, seguidas das de crédito e rurais. O resultado do Gráfico 1 chama a atenção e destaca a importância dos imóveis urbanos em relação aos rurais, o que reflete o desenvolvimento que aquela região sofreu ao longo da segunda metade do século XVIII. Esse movimento reflete, provavelmente, a dinâmica econômica daquela região com outras importantes praças comerciais dentro e fora dos limites do império ultramarino português. Um ponto que auxilia na análise desse processo é a crescente interligação da economia carioca, através de inúmeras redes de negócios (Pesavento, 2009; Pesavento \& Prado, 2009).

A fim de verificar o desempenho dos bens urbanos durante o declínio da extração aurífera (décadas de 1750-90), estruturou-se o gráfico abaixo. Para obter um resultado mais preciso, calculou-se a tendência (média móvel) dos valores médios dos bens urbanos e rurais. Os resultados estão dispostos no Gráfico 2 abaixo.

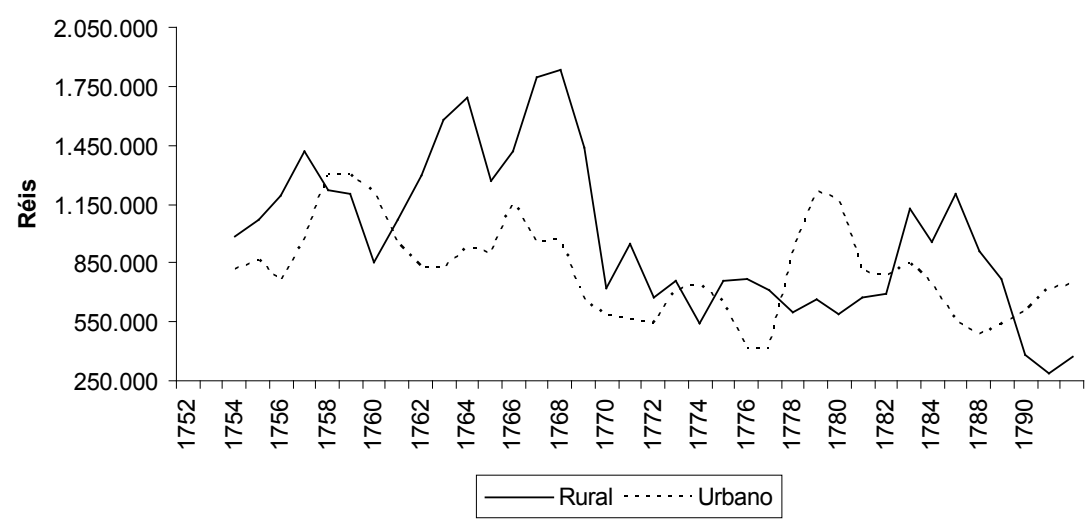

Gráfico 2 - Média móvel anual dos preços dos bens urbanos e rurais: 1750-90* Fonte: AN, escrituras públicas depositadas no $1^{\circ}, 2^{\circ}$ e $4^{\circ}$ Ofício de Notas. Elaboração própria.

O gráfico acima aponta para uma tendência conhecida (Fragoso, 1998), qual seja, a de que os valores dos bens urbanos se sobressaem sobre o preço dos rurais em fins da década de 1780. Contudo, revela um comportamento de queda dos bens urbanos depois de 1758 . A tendência declinante só se recupera em fins da década de 1770, para voltar a arrefecer durante o início da década de 1780, voltando 
a crescer no final da mesma década. Outro indicador que sugere uma queda no valor dos bens urbanos no termo da cidade do Rio de Janeiro é a análise do seu valor médio por logradouro, exposto no quadro abaixo.

Quadro 1 - Valor médio dos bens urbanos (casa térrea) no Rio de Janeiro: 1750-90*

\begin{tabular}{lllll}
\hline \multirow{2}{*}{ Logradouro } & $1750-59$ & $1760-69$ & $1770-79$ & $1780-90$ \\
\cline { 2 - 4 } Rua da Ajuda & 409.133 & 361.000 & 272.725 & 170.000 \\
Rua da Cadeia & 650.000 & 506.000 & 420.714 & 650.000 \\
Rua do Cano & 400.000 & 259.950 & 287.270 & 352.900 \\
Rua da Direita & 866.667 & 648.333 & 430.000 & 539.167 \\
Rua dos Pescadores & 890.000 & 592.500 & 786.000 & 1.150 .000 \\
Rua do Rosário & 683.333 & 564.517 & 445.700 & 610.200 \\
Rua de trás do Hospício & 437.100 & 290.000 & 302.667 & 480.800 \\
Rua de São Pedro & 725.167 & 355.900 & 516.943 & 400.000 \\
Rua das Violas & 240.000 & 200.000 & 460.300 & 707.100 \\
Rua dos Ourives & 623.600 & 587.200 & 660.000 & 355.200 \\
\hline Média & 592.500 & 436.540 & 458.232 & 541.537 \\
\hline
\end{tabular}

Fonte: AN, escrituras públicas depositadas no $1^{\circ}, 2^{\circ}$ e $4^{\circ}$ Ofício de Notas. Elaboração própria. *Em Réis.

Novamente, durante o período 1760-69, verifica-se uma queda no valor médio dos bens urbanos (casas térreas). Como no Gráfico 2, os valores se recuperam nas décadas seguintes, mas não chegam a recuperar os valores da década de 1750-59. Resta uma questão: como estabelecer uma relação entre os resultados encontrados e a crise aurífera? O argumento apresentado é o de que o valor dos bens urbanos serve como uma proxy para mensurar o nível de atividade do termo da cidade do Rio de Janeiro, pois o preço do imóvel reflete o comportamento conjuntural da economia (oferta e demanda).

Além disso, apesar de não apresentar uma relação linear, os negócios envolvendo bens urbanos estavam concentrados ${ }^{9}$ com os homens de negócios (Pesavento, 2009; Sampaio, 2003; Fragoso, 1998). Estes, por sua vez, estavam ligados à dinâmica do nível de atividade do-

9 O valor total dos bens urbanos somou mais de 550 Contos de Réis. Infelizmente, muitas escrituras não tinham informações sobre o comprador ou vendedor, assim retiraram-se, do valor total, 150 Contos de Réis. Dos 400 Contos de Réis restantes, os homens de negócio (ou que vivem de seu negócio) importaram mais de 225 Contos de Réis (56\%). 
méstico, uma vez que atendiam, grosso modo, a demanda interna. Assim, provavelmente, quanto maior o preço do bem urbano, maior o volume da atividade econômica do termo da cidade do Rio de Janeiro. Portanto, o resultado do gráfico acima sugere que o nível de atividade carioca sofreu com a retração da extração aurífera mineira.

Por outro lado, o mesmo gráfico mostra o predomínio dos bens rurais sobre os urbanos em boa parte do período 1750-1790. Esse movimento seria um retorno às atividades rurais? Para aprofundar o resultado encontrado no gráfico acima, elaborou-se o Quadro 1, o qual mostra os valores médios para os negócios rurais e urbanos.

Quadro 2 - Valor médio e mediano dos negócios rurais e urbanos no Rio de Janeiro: 1750-90*

\begin{tabular}{lcccc}
\hline & $1750-59$ & $1760-69$ & $1770-79$ & $1780-90$ \\
\cline { 2 - 5 } Engenho - VM & 5.004 .954 & 11.179 .867 & 5.836 .832 & 9.018 .000 \\
Engenho - Mediana & 3.693 .600 & 9.800 .000 & 6.500 .000 & N.I. \\
Engenho- NE & 12 & 12 & 6 & 2 \\
Loja - VM & 8.261 .496 & 1.784 .167 & 3.617 .691 & 2.176 .916 \\
Loja - Mediana & 8.590 .495 & 2.456 .600 & 1.010 .414 & 1.591 .544 \\
Loja - NE & 4 & 3 & 10 & 15 \\
\hline
\end{tabular}

Fonte: AN, escrituras públicas depositadas no $1^{\circ}, 2^{\circ}$ e $4^{\circ}$ Ofício de Notas. Elaboração própria.

* Em Réis.

Quando se comparam os valores dos negócios urbanos (lojas) e rurais (engenho), observa-se que a mediana de loja (geralmente de secos e molhados e de tecidos importados ${ }^{10}$ apresenta uma forte queda entre 1770-79, só se recuperando no período 1780-90. Os engenhos, ao contrário, mostram um comportamento distinto, isto é, forte aumento do valor médio e da mediana (com destaque para o desempenho entre 1760-69).

Nesse sentido, existe uma clara prevalência dos negócios rurais sobre os urbanos, o que não deixa de ser interessante, pois se sabe da importância do comércio e de setores ligados ao mercado interno no Rio de Janeiro depois de 1750. Portanto, o resultado sugere um "renascimento agrícola" na medida em que a demanda por bens imóveis rurais parece ter se elevado na década de 1760 (coincidindo com o

\footnotetext{
${ }^{10}$ Infelizmente, a análise das escrituras está restrita a um pequeno conjunto de informações, o que não permite um aprofundamento sobre a organização de uma loja de fazendas ou de um engenho.
} 
movimento de queda da extração aurífera) associado a um arrefecimento da atividade econômica carioca.

Uma interpretação adicional, com base nos dados do quadro acima, é o fato de que se o mercado carioca sofreu com a queda da extração aurífera, o nível de renda deve ter diminuído. Nesse sentido, a demanda provavelmente caiu, o que desvaloriza as lojas que atendiam ao mercado interno, que se reflete no seu preço de venda. Encontrou-se movimento oposto no valor dos bens rurais (mais vinculados às oscilações da economia internacional), especialmente durante a década de 1760, justamente quando do início da trajetória decrescente da extração aurífera (Pinto, 1979). Evidentemente, para reforçar estes resultados, a análise não pode ficar restrita ao comportamento do valor dos bens imóveis urbanos e rurais.

A fim de aprofundar o impacto da crise aurífera sobre a economia carioca, deve-se analisar outros indicadores. Entre eles, selecionou-se o volume de empréstimos concedidos no termo da cidade do Rio de Janeiro. O crédito é outra variável que serve como proxy para sopesar o ritmo da economia do Rio de Janeiro. As escrituras de dinheiro a razão de juros ou de dívida e obrigação (denominação das escrituras de crédito) eram uma importante forma de se obter acesso à lide mercantil, ou mesmo a um novo bem imóvel. Os resultados obtidos, a partir da análise de mais de 500 escrituras de empréstimo, estão no Quadro 3 abaixo.

Quadro 3 - Valor total, médio e mediano das escrituras de empréstimo: 1750-90*

\begin{tabular}{lcccc}
\hline & $1750-59$ & $1760-69$ & $1770-79$ & $1780-90$ \\
\cline { 2 - 5 } VT & 131.852 .561 & 57.852 .994 & 159.547 .450 & 144.322 .464 \\
VM & 1.468 .431 & 890.170 & 1.089 .921 & 626.124 \\
Mediana & 737.200 & 645.000 & 400.000 & 315.510 \\
NE & 81 & 67 & 164 & 223 \\
\hline
\end{tabular}

Fonte: AN, escrituras públicas depositadas no $1^{\circ}, 2^{\circ}$ e $4^{\circ}$ Ofício de Notas. Elaboração própria.

*Em Réis.

Novamente, e como observado para os valores dos bens urbanos durante o período 1760-69, ocorreu uma redução no número e no volume de empréstimos. Frente a um período de baixa atividade econômica, os agentes ficam avessos ao risco, o que se traduz em falta de liquidez. Portanto, o resultado do quadro acima, para 1760-69, 
sugere uma redução do nível de atividade econômica carioca durante o período. O comportamento da mediana também pode revelar uma tendência de queda da economia do Rio de Janeiro, ao menos até o início de 1790. Para aprofundar os resultados obtidos no quadro acima, estruturou-se a média móvel anual dos empréstimos, conforme aponta o gráfico abaixo.

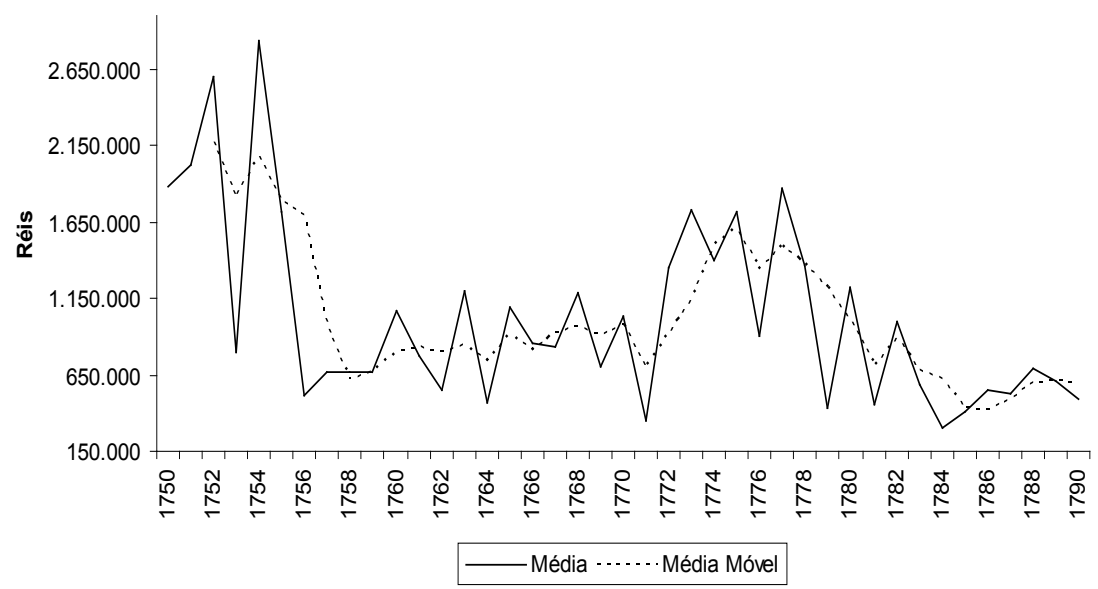

Gráfico 3 - Média e média móvel anual dos empréstimos no Rio de Janeiro: 1750-90 Fonte: AN, escrituras públicas depositadas no $1^{\circ}, 2^{\circ}$ e $4^{\circ}$ Ofício de Notas. Elaboração própria.

Novamente, parece nítida a queda na atividade econômica em fins da década de 1750 e durante a de 1760 . O volume de empréstimos recupera-se entre 1772-80, mas cai novamente em fins da década de 1780. Quando se analisam os principais setores credores da sociedade do Rio de Janeiro, Quadro 4 abaixo, percebe-se uma perda de ritmo da participação dos homens de negócio durante a década de 1760 . 
Quadro 4 - Valor total das escrituras de empréstimo por segmento social: 1750-90*

\begin{tabular}{lccccc}
\hline \multicolumn{1}{c}{ Classe Social } & $1750-59$ & $1760-69$ & $1770-79$ & $1780-90$ & Total \\
\hline Homem de Negócio & 26.015 .462 & 17.108 .496 & 61.848 .304 & 40.502 .626 & 145.474 .888 \\
Capitão & 7.724 .177 & 700.000 & 26.085 .204 & 25.747 .801 & 60.257 .182 \\
Ordem de Cristo & 4.200 .000 & 500.000 & 21.150 .220 & 8.183 .147 & 34.033 .367 \\
Viúva/Dona & 4.333 .768 & 3.920 .000 & 2.180 .000 & 2.979 .680 & 13.413 .448 \\
lgreja & 16.564 .518 & 6.780 .000 & 7.341 .200 & 3.635 .500 & 34.321 .218 \\
"Vivem de seu negócio" & 955.400 & 0 & 4.368 .345 & 9.003 .799 & 14.327 .544 \\
\hline
\end{tabular}

Fonte: AN, escrituras públicas depositadas no $1^{\circ}, 2^{\circ}$ e $4^{\circ}$ Ofício de Notas. Elaboração própria. *Em Réis.

Os diferentes segmentos sociais do Quadro 4 somam mais de 301 contos de réis, o que representa $62 \%$ do valor total da amostra de escrituras de empréstimo coletadas no AN e confirma o alto grau de concentração desse mercado. Mais uma vez, o período 1760-69 aparece com um movimento de queda, refletindo, provavelmente, o arrefecimento do "giro do comércio" e da atividade econômica. Naturalmente, os setores mais vinculados com o comportamento da economia doméstica (como os homens de negócio) são os mais sensíveis a queda do nível de atividade carioca, fato que auxilia na explicação da redução da participação do crédito de setores ligados à movimentação mercantil (como os que "vivem de seu negócio"). Daí a importância das viúvas e da Igreja num momento de declínio da atividade econômica, uma vez que sua renda não estava diretamente vinculada ao comportamento da economia.

Por sua vez, os homens de negócio ficam à mercê de suas flutuações. Assim, quando a economia atravessa um período de dificuldade, como parece em 1760, quem possui uma renda "permanente" acaba exercendo uma maior participação no mercado de crédito. Outro dado que auxilia na análise sobre o nível de atividade econômica é a evolução do nível de preços. O resultado consta no Gráfico 4 abaixo. 


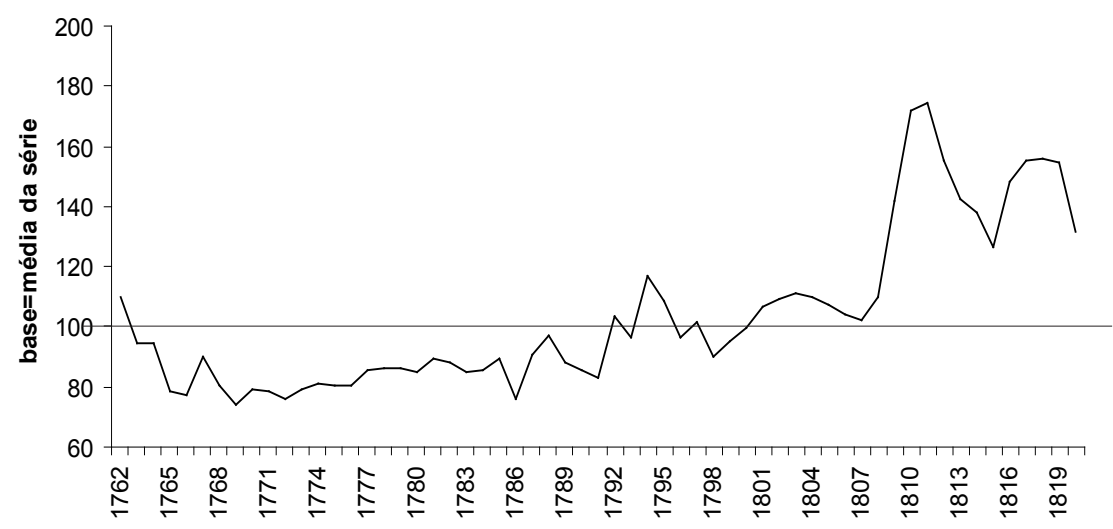

Gráfico 4 - Evolução dos preços anuais no Rio de Janeiro: 1762-1820

Fonte: Johnson Jr (1973). Elaboração própria.

Pelo gráfico acima, percebe-se que somente em fins do XVIII o nível de preços apresenta uma trajetória de alta. Esse movimento fica mais claro pós 1808, ante a chegada da Corte ao Rio de Janeiro. Além da maior demanda frente a uma estrutura de oferta posta, o comportamento oportunista aflora, uma vez que o principal comprador é o Rei e a sua Corte. De todo modo, o Gráfico 4 mostra que o processo inflacionário ocorreu depois de 1790. Isso é outro indicador de que a atividade econômica do Rio de Janeiro, especialmente na década de 1760 e 1770, provavelmente, sofre um período de estagnação.

Outra variável importante para perceber o nível de atividade do termo da cidade do Rio de Janeiro é a arrecadação da Coroa via contratos régios. O Gráfico 5 mostra a média anual da arrecadação dos seguinte contratos régios: subsídio grande e pequeno dos vinhos, subsídio da aguardente do Reino e Ilhas, subsídio do azeite doce, guarda costa, subsídio da aguardente da terra (geribita), passagens dos rios Paraíba e Paraibuna, passagens do rio São João, direito dos escravos que vão para as Minas, dízima da chancelaria, novos direitos das provisões de cartas de seguro, guindastes, tabaco e mercês. 


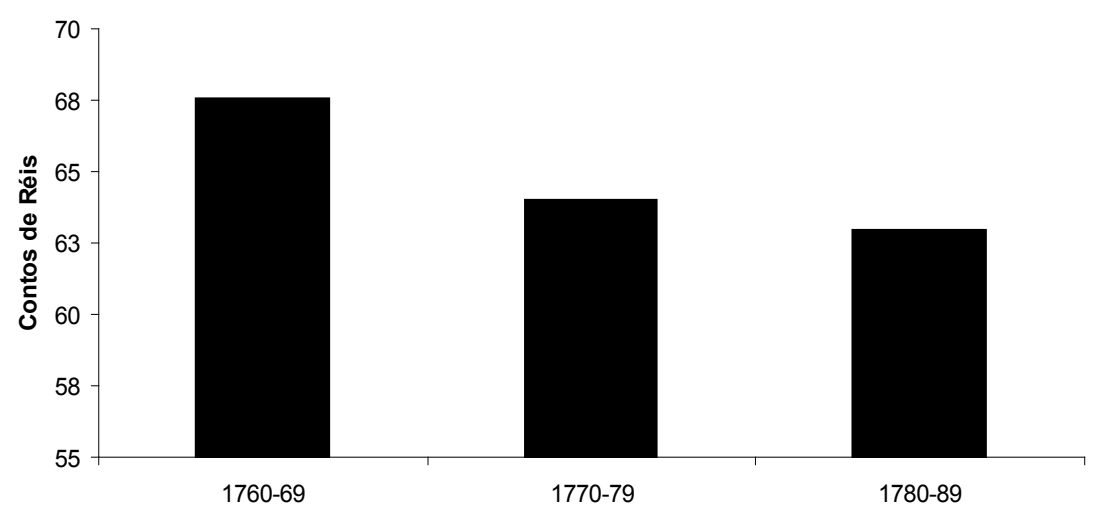

Gráfico 5 - Média anual da arrecadação de contratos régios*: 1760-89

Fonte: ANTC, livros 4132, 4057, 4058; AHU, cx.181, doc.13281. Elaboração própria.

O gráfico acima foi composto pela soma da arrecadação (ou preço) do contrato régio que envolve a economia do Rio de Janeiro. O resultado mostra que a década de 1760 não apresenta uma queda frente às décadas de 1770 e 1780, mas pelo contrário, uma arrecadação maior. A fim de capturar a tendência da série, estruturou-se a média móvel anual do rendimento dos mesmos contratos que compõem o Gráfico 6.

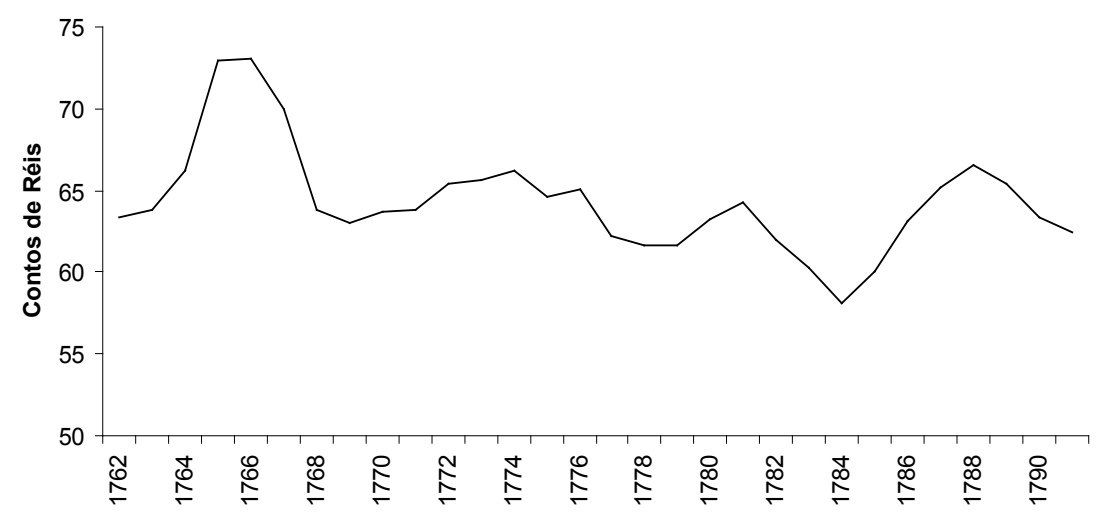

Gráfico 6 - Média móvel anual da arrecadação de contratos régios: 1762-90

Fonte: idem anterior. Elaboração própria. 
A média móvel anual revela uma queda da arrecadação daqueles contratos em fins da década de 1760 e a sua recuperação apenas em fins da década de 1780 . Os resultados, novamente, sugerem que a economia carioca pode ter atravessado uma crise econômica em fins de 1760 a 1790. Contudo, os contratos que compõem os gráficos acima não contemplam uma das principais fontes de receita da Coroa no Rio de Janeiro, a dízima da alfândega.

A dízima e a senhoriagem realizada pela Casa da Moeda do Rio de Janeiro representavam, aproximadamente, mais de 65\% da arrecadação da Coroa no Rio de Janeiro (Pesavento, 2007). A dízima é um imposto cobrado sobre $1 / 10$ do valor das mercadorias exportadas e importadas que ingressassem no porto do Rio de Janeiro. Esse imposto reflete a pujança de uma economia, uma vez que revela, grosso modo, a capacidade de realizar transações econômicas com o exterior (medindo a demanda interna e externa). Aqui, coletou-se a arrecadação e não o valor do contrato, uma vez que reflete com maior precisão o ritmo do fluxo de mercadorias do porto carioca, dando uma maior dimensão, a princípio, da movimentação econômica fluminense.

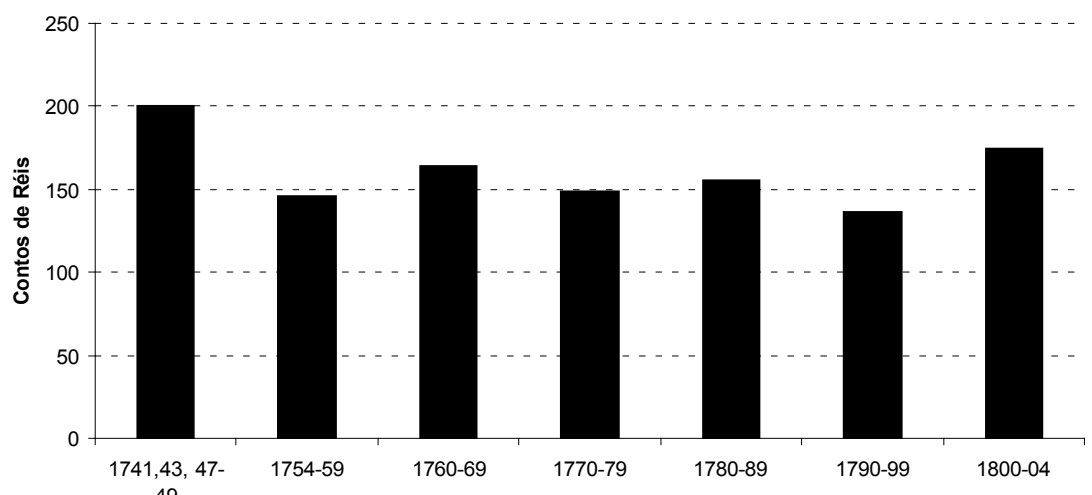

Gráfico 7 - Evolução da média da arrecadação dos direitos da dízima da alfândega do Rio de Janeiro: 1741-1804

Fonte: 1741: AHU, cx.35, doc.3656; 1743: AHU, cx.37, doc.3882; 1747-8: AHU, cx.42, doc.4317; 1749: AHU, cx.43, doc.4408; 1754-5: AHU, cx.51, doc.5083; 1756: AHU, cx.52, doc.5246; 1757-61: AHU, cx.66, doc.6209; 1762-92: ANTC, livro 4057; 1793: média aritmética entre 1792 e 1794. 1794-6: AHU, cx.179, doc.13142; 1797: média aritmética entre 1796 e 1799; 1798-9: AHU, cx.181, doc.13281, 1800-02: aproximação por AHU, cx.211, doc.14697; 1803: AHU, cx.271, doc.14959. Elaboração própria. 
Pelo gráfico acima, parece nítido que a arrecadação da dízima da alfândega não apresenta uma queda na década de 1760. Pelo contrário, seu desempenho só perde para o início do século XIX. Por outro lado, a média do período 1754-59 mostra uma queda frente aos anos de 1741, 1743, 1747-49, o que sinaliza uma perda da dinâmica da atividade econômica, sugerindo não uma crise, mas sim uma estagnação da atividade econômica fluminense. No entanto, com exceção ao período $1741,1743,1747-49$, a arrecadação não sofre grandes alterações, sugerindo que a queda do ouro não atingiu o "setor externo" do Rio de Janeiro no período estudado. Para realizar uma melhor aproximação do comportamento da arrecadação da dízima, calculou-se a sua média móvel anual.

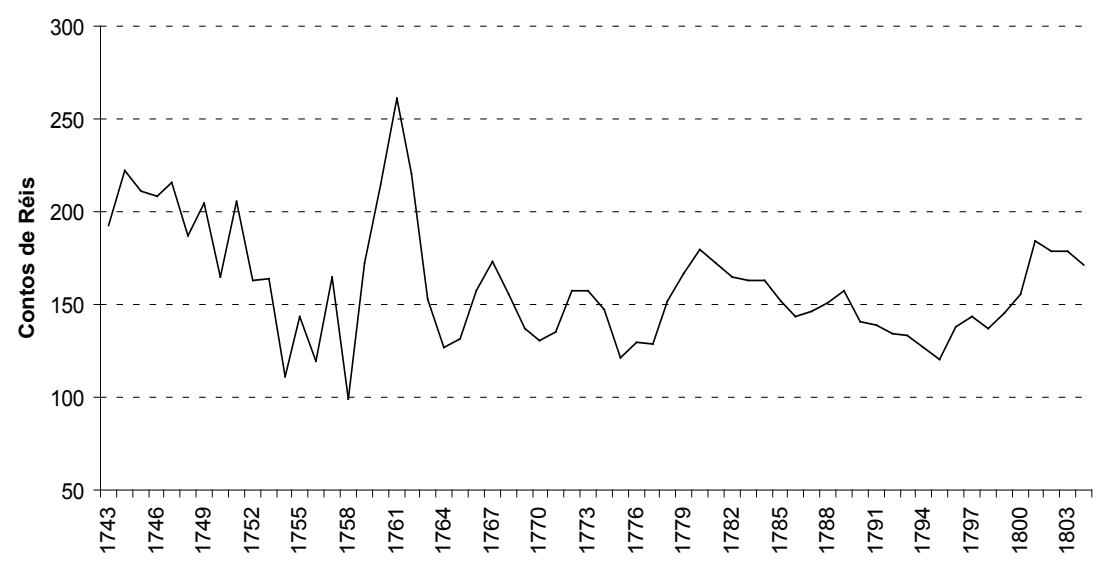

Gráfico 8 - Média móvel anual da dízima da alfândega do Rio de Janeiro: 1743-1804* Fonte: idem anterior. Elaboração própria.

*Para os anos sem dados calculou-se a média aritmética simples.

Por este gráfico, verificam-se três movimentos: queda da arrecadação até o final da década de 1750, recuperação no início da de 1760 e, posteriormente, flutuações em torno de 150 contos de réis. Fatores condicionaram esses resultados: questões como o cuidado na coleta dos dados pela autoridade local (reforma pombalina), o aumento do cerco ao contrabando e a atividades ilícitas como um melhor controle na entrada de embarcações na Baía da Guanabara. Outro exemplo é dado em novembro de 1766, quando o Conde da Cunha comunicou 
ao secretário de Estado da Marinha e Ultramar, Francisco Xavier de Mendonça Furtado:

"a sugestão do procurador da Coroa e Fazenda Real, Alexandre Nunes Leal, de um novo regulamento para a administração da mesma Alfândega, ressaltando que o seu administrador não deveria ser negociante, para evitar irregularidades, tais como evasão de mercadorias e remessa de ouro e diamantes nos maços de cartas particulares, como aconteceu com os comerciantes Manoel Barbosa dos Santos e João Caetano Sacomano, punidos exemplarmente." (AHU, avulsos RJ, cx.79, doc.7110).

Além disso, devem-se incorporar diversos fatores exógenos como as guerras no sul da colônia, que desorganizaram a arrecadação de tributos. Cabe reforçar que precisar-se-ia de mais informações para um resultado mais conclusivo (como a arrecadação durante toda a década de 1740 e 1750). Contudo, sabe-se que na segunda metade dos setecentos a dívida acumulada da Coroa (cinco milhões de cruzados) com os comerciantes locais (negociantes na sua grande maioria) prejudicava o giro do comércio fluminense (Lobo, 1978).

De todo o modo, segundo os dados do gráfico acima, a década de 1760 não pode ser considerada de crise econômica. Por outro lado, é claro que a arrecadação só atingiu o mesmo patamar de 1767, no ano de 1780 e em fins da década de 1790, o que pode sugerir uma desaceleração do nível de atividade fluminense nas décadas de 1770 a 1790. Novamente, fatores exógenos e a escassez de informações primárias limitam os resultados, transformando-os em indicadores que não podem ser tomados em caráter definitivo.

O objetivo de reunir os dados trabalhados na presente seção foi o de tentar reconstituir o comportamento da economia do termo da cidade do Rio de Janeiro durante o período de queda da extração aurífera. Abstruso sintetizar os resultados encontrados a fim de responder aos objetivos delineados, contudo se podem estabelecer linhas gerais sobre o desempenho da economia carioca entre 1750-90. Por exemplo, quando se analisa os valores dos bens urbanos e o volume 
de empréstimos concedidos, percebe-se um desempenho similar, qual seja, queda durante a década de 1760 e recuperação nas décadas posteriores.

Por outro lado, a arrecadação média da Coroa no Rio de Janeiro não sofreu um declínio acentuado durante o período 1760-69. Este movimento de baixa foi verificado na década seguinte, muito embora a arrecadação média (em especial da dízima da alfândega) não se altere significativamente no período estudado. Por fim, chama a atenção o comportamento altista do valor dos bens rurais durante a década de 1760. Assim, podem-se perceber, com base no painel de dados construído na presente seção, dois aspectos importantes do comportamento da economia do termo da cidade do Rio de Janeiro durante o arrefecimento aurífero:

1. o nível de atividade carioca não experimentou uma crise ou depressão econômica, mas sim uma estagnação;

2. ante o aumento do valor dos bens rurais, percebeu-se um revigoramento das atividades agrícolas.

A fim de reforçar os resultados encontrados, foram realizados exercícios cliométricos com o objetivo de verificar, estatisticamente, a relação entre o arrefecimento da extração aurífera sobre a economia carioca.

\section{Crise, Estagnação ou nada disto: O Auxílio Cliométrico para o Debate}

Até o presente momento, atentou-se para a análise de alguns indicadores do nível de atividade da economia do Rio de Janeiro. Nesse sentido, constatou-se que durante o período de queda da extração aurífera (pós 1750) os indicadores selecionados do comportamento da economia carioca, grosso modo, sofreram um processo de arrefecimento, especialmente durante a década de 1760. Contudo, devem-se reforçar os resultados obtidos anteriormente. Para tal, realizou-se, na presente seção, uma análise estatística ${ }^{11}$ a fim de estabelecer a

11 Cf Feinstein \& Thomas (2002); Demeulemeester \& Diebolt (2007). 
relação entre a queda da extração aurífera e o nível de atividade econômica do termo da cidade do Rio de Janeiro.

Entre as proxies empregadas para mensurar o nível de atividade carioca estão o preço dos bens urbanos (LURB), preço dos bens rurais $(L R U R)$ e o volume de crédito concedido (LCRE). A variável para representar o ciclo mineiro é o volume de ouro arrecadado com a cobrança do imposto "quinto do ouro" (LOUR). ${ }^{12}$ Empregou-se o preço $^{13}$ internacional do açúcar (LPAC) como variável de controle ante a importância das exportações da commodity na formação da renda do Rio de Janeiro (Pesavento, 2009).

Deve-se alertar que as estimativas têm caráter unicamente demonstrativo e, portanto, devem ser vistas como um indicador. A elaboração das equações teve como marco referencial os fatos vislumbrados na documentação primária citada. Todas as séries utilizadas são anuais, entre 1750 a 1790, e os valores, em réis, ou quilogramas, foram convertidos em logaritmo natural. No presente estudo, os valores foram estimados no software Eviews 4.1 e empregaram-se mínimos quadrados ordinários (MQO) com correção de autocorrelação na matriz de dados Newey-West. As séries são estacionárias como apontam os testes Phillips-Perron e Kwiatkowski-Phillips-Schmidt-Shin disponíveis no anexo.

Conforme os resultados apresentados na seção anterior, a economia do termo da cidade do Rio de Janeiro não sofreu uma depressão, mas sim uma estagnação. A fim de reforçar estes dados estimaram-se as seguintes equações.

$$
\begin{aligned}
& \operatorname{LRUR}_{t}=C+\beta_{1} \text { LOUR }_{t}+\beta_{2} L_{P A C_{t-2}}+\varepsilon_{t} \\
& \operatorname{LURB}_{t}=C+\beta_{1} \text { LOUR }_{t}+\beta_{2} L P A C_{t-3}+\varepsilon_{t} \\
& \operatorname{LCRE}_{t}=C+\beta_{1} \text { LOUR }_{t}+\beta_{2} L P A C_{t-2}+\varepsilon_{t}
\end{aligned}
$$

Como os dados foram transformados em logaritmo natural, os coeficientes $\beta_{1}$ e $\beta_{2}$ mensuram suas elasticidades. Assim, em (1) para o

12 Os dados foram obtidos em Pinto (1979).

13 Os dados foram obtidos em Maxweel (1973). 
aumento de $1 \%$ na extração aurífera (LOUR), por exemplo, quanto \% o preço dos bens rurais (LRUR) variam? Com isso, se pode perceber, quantitativamente, o impacto de uma variação do ciclo do ouro mineiro sobre indicadores econômicos do Rio de Janeiro, robustecendo os resultados encontrados na seção anterior. As estimativas de (1), (2) e (3) estão listadas no quadro abaixo.

Quadro 5 - Valores estimados dos modelos (1), (2) e (3)

\begin{tabular}{cccccc}
\hline Equação & $\mathbf{C}$ & $\boldsymbol{\beta}_{1}$ & $\boldsymbol{\beta}_{2}$ & $\mathbf{R}^{2}$ Ajustado (\%) & Teste resíduos $^{\#}$ \\
\hline (1) & $-5,93^{\star}$ & 1,69 & 2,01 & 49 & 0,01 \\
$(\mathbf{2})$ & 13,08 & $0,36^{\star *}$ & $-0,56^{\star}$ & 7 & 0,68 \\
$(3)$ & 15,11 & $0,54^{\star}$ & $-1,40$ & 24 & 0,68 \\
\hline
\end{tabular}

Fonte: Elaboração própria. \# Valor p do teste Jarque-Bera. Significativo a $1 \%$, ${ }^{*}$ significativo a $5 \%,{ }^{* *}$ significativo a $10 \%$.

Um exercício adicional para verificar a acuidade dos resultados expostos acima (além dos testes de raiz unitária) é o de analisar a normalidade dos resíduos (dispostos na última coluna do Quadro 5). O teste Jarque-Bera (JB) ${ }^{14}$ indicou que a Equação (1) não apresenta distribuição normal. Por outro lado, o seu comportamento pode ser considerado aproximadamente normal, quando se visualiza o $Q Q$ Plot (no anexo). De todo o modo, deve-se ter parcimônia no exame dos estimadores da referida equação. Já os coeficientes estimados das Equações (2) e (3) podem ser avaliados sem maiores restrições.

O primeiro resultado que chama a atenção é a relação positiva entre o ciclo aurífero e os indicadores da atividade econômica do termo da cidade do Rio de Janeiro. Em (2), por exemplo, para um aumento de $1 \%$ na extração de ouro, o preço do bem urbano sobe $0,36 \%$, revelando a influência da atividade mineradora sobre a economia carioca. O mesmo movimento é encontrado em (3), ou seja, o volume de crédito concedido também responde positivamente $(0,54 \%)$ frente a um aumento na extração aurífera. Já em (1), essa tendência se intensifica (aumento de 1,69\% sobre o preço dos bens rurais). Diante dos valores dos coeficientes estimados em (1), (2) e (3) sugere-se que o arrefecimento do ouro pode ter interferido sobre o nível de atividade do Rio de Janeiro, em especial no mercado de crédito e de bens rurais.

$\overline{14}$ O teste Shapiro-Wilk para normalidade da amostra apontou o mesmo resultado do Quadro 5. 
Outro resultado que se destaca é o coeficiente de correlação ajustado alto em (1) que chegou a 49\%. Em (3) também foi significativo, pois atingiu $24 \%$, isto é, o preço internacional do açúcar e a extração aurífera "explicam" 24\% do volume de crédito concedido no Rio de Janeiro entre 1750-90. Estes resultados são confirmados quando se verifica a correlação entre as variáveis. Por exemplo, entre o volume de empréstimos concedidos (LCRE) e a variável representativa da atividade mineradora (LOUR) existe uma correlação positiva de $42 \%$. Já entre o valor dos bens urbanos (LURB) e o ciclo aurífero (LOUR) chega aos 29\% ao passo que com os bens rurais (LRUR) atinge os expressivos $56 \%$.

Um ponto adicional na análise é a relação negativa que exerce o preço internacional do açúcar (com defasagem de dois anos) sobre o volume de crédito carioca. Segundo os resultado encontrados no Quadro 5, para um aumento de $1 \%$ no preço da commodity, o volume de crédito se contrai $1,4 \%$. Esse resultado sugere que não apenas os condicionantes externos (LPAC) determinam a dinâmica do crédito carioca no período 1750-90. O mesmo movimento é observado quando se analisa o coeficiente $(-0,56 \%)$ do preço internacional do açúcar na Equação (2). Por outro lado, o resultado de $\beta_{2}$ da Equação (1) aponta na direção oposta, qual seja, para um aumento de $1 \%$ no preço do açúcar internacional, os preços dos bens rurais elevam-se em $2 \%$, refletindo a importância do setor externo naquele mercado.

Ante os resultados encontrados, sugere-se que existiu uma relação entre a queda da extração aurífera com a economia do termo da cidade do Rio de Janeiro. Infelizmente, não se pode mensurar com precisão o grau de interferência do declínio sobre o nível de atividade carioca. Contudo os valores estimados mostram a sua influência na dinâmica econômica do Rio de Janeiro.

\section{Conclusão}

O objetivo do presente trabalho foi o de analisar o impacto da crise aurífera sobre a economia do termo da cidade do Rio de Janeiro. Para tal, apresentou-se uma breve contextualização da economia carioca durante a segunda metade dos setecentos. Nela se pode perceber a crescente importância da região fluminense tanto política como 
economicamente. Além disto, ela experimentou uma diversificação agrícola importante para o desenvolvimento daquela região.

Um ponto de interrogação surge quando se tenta responder, com base em dados que compreende o período 1750-90, quais teriam sido os efeitos da crise aurífera mineira sobre o Rio de Janeiro. Por outro lado, o debate sobre este tema é bem conhecido. Conforme apontado na segunda seção deste artigo, Celso Furtado defende o argumento de que depois da queda do ciclo do ouro, a economia brasileira vai atravessar um período de atrofiamento do seu nível de renda e regredir para um sistema de subsistência. Dauril Alden prossegue nesta linha interpretativa, chamando a atenção para o fato de que a economia colonial vai retornar, pós 1750 , seus recursos a agricultura. Por sua vez, João Fragoso argumenta que a economia fluminense não vai experimentar uma crise, na medida em que ela já estava produzindo para o mercado interno.

A fim de tentar colaborar com o debate e na ausência de dados para o período 1750-90, buscou-se construir um painel de dados para perceber qual foi o impacto da crise aurífera sobre a economia do termo da cidade do Rio de Janeiro. Com base em mais de 6.500 escrituras públicas de compra e venda, reuniu-se um conjunto de indicadores que remontaram o ritmo do nível de atividade carioca justamente no momento da queda da extração aurífera. Cabe a ressalva de que os dados levantados são indicadores do nível de atividade. Portanto, não podem ser tomados em caráter definitivo.

Entre os resultados encontrados se destaca o desempenho global do valor dos bens urbanos, que durante o período 1750-90 tiveram um resultado acima dos bens rurais. Esse movimento pode ter refletido a dinâmica econômica daquela região com outras importantes praças comerciais dentro e fora dos limites do império ultramarino português, através de inúmeras redes de negócios. Entretanto, quando se analisa os resultados por décadas, verifica-se que os valores dos bens urbanos e o volume de empréstimos concedidos, especialmente durante a 1760-69, sofreram uma forte retração. Apesar da recuperação de seus valores médios durante as décadas de 1770 e 1780, não se percebe um desempenho similar ao da década de 1750. Assim, podese concluir que durante a crise aurífera dois setores importantes da economia carioca foram impactados e a velocidade de recuperação foi lenta. 
Comportamento distinto teve o valor médio dos bens rurais que se valorizaram justamente quando a queda extração aurífera mais se intensificava. Esses resultados apontam para um renascimento agrícola (intensificado pelo processo de diversificação agrícola promovido por Lavradio e Pombal no Rio de Janeiro). Já quando se analisa a arrecadação média da Coroa no Rio de Janeiro, verifica-se que esta não sofreu um declínio acentuado durante o período 1760-69. Esse movimento de baixa foi verificado na década seguinte, muito embora a arrecadação média (em especial da dízima da alfândega) não se altere significativamente no período estudado.

$\mathrm{Na}$ tentativa de aprofundar os resultados encontrados na segunda seção, recorreu-se aos exercícios estatísticos. Com o auxílio deste instrumental, tem-se a oportunidade de reforçar as conclusões construídas. Com isso, conseguiu-se verificar, quantitativamente, a relação entre o ciclo aurífero mineiro e o nível de atividade da economia carioca. Evidentemente que as estimativas devem ser analisadas como indicativos e com parcimônia, contudo sugerem a importância que teve a atividade mineradora para o mercado de crédito, de bens urbanos e rurais.

Com base nos resultados encontrados no presente trabalho conclui-se que existiu uma relação entre a queda da extração aurífera com a economia do termo da cidade do Rio de Janeiro. Mesmo não se mensurando com precisão o grau de interferência do declínio aurífero sobre o nível de atividade carioca, pode-se perceber que a economia carioca não experimentou uma crise ou depressão econômica, mas sim uma estagnação. Além disso, verificou-se um revigoramento das atividades agrícolas fluminenses. O que pode auxiliar na explicação desses resultados é o fato de que a economia fluminense não se restringia apenas a oscilação da economia colonial ou da economia internacional, mas sua conjugação. Esse cenário revela um marco analítico que permite ampliar a formulação de novas hipóteses, na medida em que expande a análise feita a partir da dicotomia interno e externo. 


\section{Referências}

ALDEN, Dauril. O período final do Brasil colônia, 1750-1808. IN: Bethell, Leslie (org.). História da América Latina: a América Latina colonial. São Paulo: Edusp, 1999, vol.2.

AZEVEDO, João Lúcio de. O Marquês de Pombal e sua época. São Paulo: Alameda, 2004.

BOXER, Charles. A Idade de ouro do Brasil. São Paulo: Companhia Editora Nacional, 1969.

O Império marítimo português: 1415-1825. São Paulo: Companhia das Letras, 2002.

BROWN, Larissa V. Internal commerce in a colonial economy: Rio de Janeiro and it's hinterland, 1790-1822. University of Virginia: Charlottesville, 1986. Tese de doutorado.

CARRARA, Ângelo Alves. Fiscalidade e conjunturas financeiras do Estado do Brasil, 1607-1718. Seminário Hermes \& Clio, FEA-USP, São Paulo, 2008.

Minas e currais: produção rural e mercado interno de Minas Gerais, 1674-1807. Juiz de Fora: Editora da UFJF, 2007.

CAVALCANTI, Nireu Oliveira. O Rio de Janeiro setecentista: a vida e a construção da cidade da invasão francesa até a chegada da Corte. Rio de Janeiro: Jorge Zahar, 2004.

CHAVES, Claudia Maria das Graças. Perfeitos negociantes: mercadores das Minas setecentistas. São Paulo: Annablume, 1999.

DEMEULEMEESTER, Jena-Luc; Diebolt, Claude. How much could economics gain from history: the contribution of cliometrics. Heidelberg: Cliometrica, v.1, n.1, april 2007, pp.7-17.

FALCON, Francisco. A época pombalina: política econômica emonarquia ilustrada. São Paulo: Ática, 1982.

. O império luso-brasileiro e a questão da dependência inglesa - um estudo de caso: a política mercantilista durante a Época Pombalina, e a sombra do Tratado de Methuen. Nova Economia: Belo Horizonte, vol.15, n.2, maio-agosto 2005, pp.11-34.

FEINSTEIN, Charles H; Thomas, Mark. Making history count: a primer in quantitative methods for historians. Cambridge: Cambridge, 2002.

FLORENTINO, Manolo. Em costas negras: uma história do tráfico de escravos entre a África e o Rio de Janeiro. São Paulo: Companhia das Letras, 1997.

FLORY, Rae. Bahian Society in the mid-colonial period: the sugar platers, tobacco growers, merchants, and artisans of Salvador and the Reconcavo, 1680-1725. University of Texas: Austin, 1978. Tese de doutorado.

FRAGOSO, João. Homens de grossa ventura: acumulação e hierarquia na praça mercantil do Rio de Janeiro, 1790-1830. Rio de Janeiro: Civilização Brasileira, 1998.

; FLORENTINO, Manolo. O arcaísmo como projeto: mercado atlântico, sociedade agrária e elite mercantil em uma economia colonial tardia. Rio de Janeiro: Civilização Brasileira, 2001.

; ALMEIDA, Carla M. de C.; Sampaio, Antônio Carlos Jucá (org.). Conquistadores e negociantes: história de elites no antigo regime nos trópicos. América lusa, séculos XVI a XVIII. Rio de Janeiro: Civilização Brasileira, 2007.

; et alli, (org). Nas rotas do império: eixos mercantis, tráfico e relações sociais no mundo português. Vitória: Edufes; Lisboa: IICT, 2006.

FURTADO, Celso. Formação econômica do Brasil. São Paulo: Editora Nacional, 1998.

FURTADO, Júnia Ferreira. Homens de Negócio: a interiorização da metrópole e do comércio nas Minas setecentistas. São Paulo: HUCITEC, 1999.

Diálogos oceânicos: Minas Gerais e as novas abordagens para uma história do Império Ultramarino Português. Belo Horizonte: Editora da UFMG, 2001.

GIL, Tiago; PESAVENTO, Fábio. Conversa de surdos: subsídio para o debate sobre o mercado interno. VI Jornada Setecentista. Curitiba, 2005. 
JOHNSON JR, HAROLD B. A preliminary inquiry into money, prices, and wages in Rio de Janeiro, 1763-1823. IN: Dauril Alden. Colonial roots of modern Brazil: papers of the newberry library conference. Berkeley: University of California Press, 1973.

LOBO, Eulália Maria Lahmeyer. História do Rio de Janeiro: do capital comercial ao capital industrial e financeiro. Rio de Janeiro: IBMEC, vol.1, 1978.

MAXWELL, Kenneth. Marquês do Pombal: o paradoxo do iluminismo. São Paulo: Paz e Terra, 1996.

. A devassa da devassa: a Inconfidência Mineira: Brasil e Portugal 1750-1808. São Paulo; Rio de Janeiro: Paz e Terra, 1973.

MONTEIRO, John. Labor systems, 1492-1850. IN: Coatsworth, H.; Cortés-Conde, Roberto; Bulmer, Thomas V. (eds). Cambridge Economic History of Latin America. Cambridge: Cambridge University Press (no prelo).

NORONHA Santos, FRANCISCO A. As freguesias do Rio antigo. Rio de Janeiro: Cruzeiro, 1965.

PESAVENTO, Fábio. O mercado interno fluminense na segunda metade do Setecentos: nota de pesquisa. VII Congresso Brasileiro de História Econômica e $8^{a}$ Conferência Internacional de História de Empresas, Aracaju, 2007.

. Um pouco antes da Corte: a economia do Rio de Janeiro na segunda metade do Setecentos. PPGE-UFF, Niterói, 2009. Tese de doutoramento.

; Prado, Fabrício. Beyond the Portuguese Atlantic: Trans and Extra-Imperial Networks in Eighteenth-Century Lisbon, Rio de Janeiro, Rio de la Plata and Liverpool. XV The World Economic History Congress, Utrecht, 2009.

PINTO, Virgílio Noya. O ouro brasileiro e o comércio anglo-português: uma contribuição aos estudos DA ECONOMIA ATLÂNTICA NO SÉCULO XVIII. SÃO PAULO: BRASILIANA, 1979.

PRADO Júnior, Caio. História Econômica do Brasil. São Paulo: Brasiliense, 2006.

SAMPAIO, Antônio Carlos Jucá de. Na encruzilhada do Império: hierarquias sociais e conjunturas econômicas no Rio de Janeiro (c.1650 - c.1750). Rio de Janeiro: Arquivo Nacional, 2003.

SCHWARTZ, Stuart B. Segredos internos: engenhos e escravos na sociedade colonial, 1550-1835. São Paulo: Companhia das Letras, 1988.

. O Brasil colonial, c.1580-1750: as grandes lavouras e as periferias. IN: Bethell, Leslie (org.). História da América Latina: a América Latina colonial. São Paulo: Edusp, 1999, vol.1-2.

SILVA, De Placido e. Vocabulário Jurídico. Rio de Janeiro: Forense, 1998.

ZEMELLA, Mafalda P. O Abastecimento da Capitania das Minas Gerais no século XVIII. São Paulo: HUCITEC, 1990. 


\section{Anexo}

\section{Quadro 6 - Estimação Equação (1)}

Dependent Variable: LRUR

Method: Least Squares

Sample(adjusted): 17521790

Newey-West HAC Standard Errors \& Covariance (lag truncation=3)

\begin{tabular}{lllll}
\hline \multicolumn{1}{c}{ Variable } & Coefficient & Std. Error & t-Statistic & Prob. \\
\hline C & -5.927860 & 2.700128 & -2.195400 & 0.0347 \\
LOUR & 1.687262 & 0.262996 & 6.415533 & 0.0000 \\
\hline R-squared & 2.008179 & 0.344121 & 5.835671 & 0.0000 \\
Adjusted R-squared & 0.511662 & Mean dependent var & & 13.49819 \\
S.E. of regression & 0.484532 & S.D. dependent var & & 0.798290 \\
Sum squared resid & 0.573141 & Akaike info criterion & & 1.798434 \\
Log likelihood & 11.82566 & Schwarz criterion & & 1.926400 \\
Durbin-Watson stat & -32.06946 & F-statistic & & 18.85972 \\
\hline \hline
\end{tabular}

\section{Quadro 7 - Estimação Equação (2)}

Dependent Variable: LURB

Method: Least Squares

Sample(adjusted): 17531790

Newey-West HAC Standard Errors \& Covariance (lag truncation=3)

\begin{tabular}{llllc}
\hline \multicolumn{1}{c}{ Variable } & Coefficient & Std. Error & t-Statistic & Prob. \\
\hline C & $\mathbf{1 3 . 0 8 0 2 8}$ & 1.797220 & 7.278063 & 0.0000 \\
LOUR & $\mathbf{0 . 3 6 1 0 0 3}$ & 0.199773 & 1.807069 & 0.0794 \\
\hline R-squared & -0.562732 & 0.273128 & -2.060326 & 0.0469 \\
Adjusted R-squared & 0.121036 & Mean dependent var & & 13.51321 \\
S.E. of regression & $\mathbf{0 . 0 7 0 8 1 0}$ & S.D. dependent var & & 0.426269 \\
Sum squared resid & 0.410900 & Akaike info criterion & & 1.134721 \\
Log likelihood & 5.909346 & Schwarz criterion & & 1.264004 \\
Durbin-Watson stat & -18.55970 & F-statistic & & 2.409805 \\
\hline \hline
\end{tabular}




\begin{tabular}{|c|c|c|c|c|}
\hline \multicolumn{5}{|c|}{$\begin{array}{l}\text { Quadro } 8 \text { - Estimação Equação (3) } \\
\text { Dependent Variable: LCRE }\end{array}$} \\
\hline \multicolumn{5}{|l|}{ Method: Least Squares } \\
\hline \multicolumn{5}{|c|}{ Sample(adjusted): 17521790} \\
\hline \multicolumn{5}{|c|}{ Newey-West HAC Standard Errors \& Covariance (lag truncation=3) } \\
\hline Variable & Coefficient & Std. Error & t-Statistic & Prob. \\
\hline C & 15.11045 & 2.742651 & 5.509434 & 0.0000 \\
\hline LOUR & 0.538466 & 0.251012 & 2.145180 & 0.0388 \\
\hline $\operatorname{LPAC}(-2)$ & -1.402831 & 0.448954 & -3.124663 & 0.0035 \\
\hline R-squared & 0.277428 & Mean dependent var & & 13.64424 \\
\hline Adjusted R-squared & 0.237285 & S.D. dependent var & & 0.546179 \\
\hline S.E. of regression & 0.476997 & Akaike info criterion & & 1.431191 \\
\hline Sum squared resid & 8.190947 & Schwarz criterion & & 1.559157 \\
\hline Log likelihood & -24.90823 & F-statistic & & 6.911005 \\
\hline Durbin-Watson stat & 2.110785 & Prob(F-statistic) & & 0.002883 \\
\hline
\end{tabular}

\section{Quadro 9 - Teste raiz unitária preço bem urbano (LRUB) Phillips-Perron}

Null Hypothesis: LURB has a unit root

Exogenous: Constant, Linear Trend

Bandwidth: 6 (Newey-West using Bartlett kernel)

\begin{tabular}{llll}
\hline & & Adj. t-Stat & Prob. $^{*}$ \\
\hline Phillips-Perron test statistic & & -5.039779 & 0.0011 \\
\hline Test critical values: & $1 \%$ level & -4.205004 & \\
& $5 \%$ level & -3.526609 & \\
& $10 \%$ level & -3.194611 & \\
\hline
\end{tabular}

*MacKinnon (1996) one-sided p-values.

Quadro 10 - Teste raiz unitária preço bem urbano (LRUB) KPSS

Null Hypothesis: LURB is stationary

Exogenous: Constant, Linear Trend

Bandwidth: 3 (Newey-West using Bartlett kernel)

\begin{tabular}{lrc}
\hline \multicolumn{2}{l}{ Kwiatkowski-Phillips-Schmidt-Shin test statistic } & LM-Stat. \\
\hline Asymptotic critical values*: & $1 \%$ level & $\mathbf{0 . 0 8 4 8 6 6}$ \\
& $5 \%$ level & 0.216000 \\
& $10 \%$ level & 0.146000 \\
\hline *Kwiatkowski-Phillips-Schmidt-Shin (1992, Table 1) & 0.119000 \\
Residual variance (no correction) & & \\
HAC corrected variance (Bartlett kernel) & 0.161187 \\
\hline
\end{tabular}


Quadro 11 - Teste raiz unitária preço bem rural (LRUR) Phillips-Perron

Null Hypothesis: LRUR has a unit root

Exogenous: Constant, Linear Trend

Bandwidth: 2 (Newey-West using Bartlett kernel)

\begin{tabular}{lllc}
\hline & & Adj. t-Stat & Prob. ${ }^{*}$ \\
\hline Phillips-Perron test statistic & & -6.409808 & 0.0000 \\
Test critical values: & 1\% level & -4.205004 & \\
& $5 \%$ level & -3.526609 & \\
& $10 \%$ level & -3.194611 & \\
\hline${ }^{*}$ MacKinnon (1996) one-sided p-values. & & & \\
Residual variance (no correction) & & & 0.428999 \\
HAC corrected variance (Bartlett kernel) & & & 0.402825 \\
\hline
\end{tabular}

\section{Quadro 12 - Teste raiz unitária preço bem rural (LRUR) KPSS}

Null Hypothesis: LRUR is stationary

Exogenous: Constant, Linear Trend

Bandwidth: 2 (Newey-West using Bartlett kernel)

\begin{tabular}{lll}
\hline & & LM-Stat. \\
\hline Kwiatkowski-Phillips-Schmidt-Shin test statistic & & 0.109130 \\
Asymptotic critical values*: & $1 \%$ level & 0.216000 \\
& $5 \%$ level & 0.146000 \\
& $10 \%$ level & 0.119000 \\
\hline *Kwiatkowski-Phillips-Schmidt-Shin (1992, Table 1) & & \\
Residual variance (no correction) & & 0.433460 \\
HAC corrected variance (Bartlett kernel) & 0.401727 \\
\hline
\end{tabular}

Quadro 13 - Teste raiz unitária preço internacional açúcar (LPAC) PhillipsPerron

Null Hypothesis: LPAC has a unit root

Exogenous: Constant, Linear Trend

Bandwidth: 1 (Newey-West using Bartlett kernel)

\begin{tabular}{lccc}
\hline & & Adj. t-Stat & Prob. $^{*}$ \\
\hline Phillips-Perron test statistic & & -2.753552 & 0.0742 \\
Test critical values: & $1 \%$ level & -3.605593 & \\
& $5 \%$ level & -2.936942 & \\
& $10 \%$ level & -2.606857 & \\
\hline
\end{tabular}

*MacKinnon (1996) one-sided p-values.

Residual variance (no correction)

0.013583

HAC corrected variance (Bartlett kernel)

0.014998 
Quadro 14 - Teste raiz unitária preço internacional açúcar (LPAC) KPSS

Null Hypothesis: LPAC is stationary

Exogenous: Constant, Linear Trend

Bandwidth: 4 (Newey-West using Bartlett kernel)

\begin{tabular}{lcc}
\hline \multicolumn{2}{l}{ Kwiatkowski-Phillips-Schmidt-Shin test statistic } & LM-Stat. \\
\hline Asymptotic critical values*: & $1 \%$ level & 0.059764 \\
& $5 \%$ level & 0.216000 \\
& $10 \%$ level & 0.146000 \\
\hline${ }^{*}$ Kwiatkowski-Phillips-Schmidt-Shin (1992, Table 1) & & 0.119000 \\
Residual variance (no correction) & & 0.023261 \\
HAC corrected variance (Bartlett kernel) & & 0.057420 \\
\hline
\end{tabular}

Quadro 15 - Teste raiz unitária quinto do ouro (LOUR) Phillips-Perron

Null Hypothesis: LOUR has a unit root

Exogenous: Constant, Linear Trend

Bandwidth: 3 (Newey-West using Bartlett kernel)

\begin{tabular}{llll}
\hline & & Adj. t-Stat & Prob. $^{*}$ \\
\hline Phillips-Perron test statistic & & -4.519236 & 0.0044 \\
\hline Test critical values: & $1 \%$ level & -4.205004 & \\
& $5 \%$ level & -3.526609 & \\
& $10 \%$ level & -3.194611 & \\
\hline
\end{tabular}

\begin{tabular}{lr}
\hline${ }^{*}$ MacKinnon (1996) one-sided p-values. & \\
\hline Residual variance (no correction) & 0.010506 \\
HAC corrected variance (Bartlett kernel) & 0.012468 \\
\hline
\end{tabular}

Quadro 16 - Teste raiz unitária quinto do ouro (LOUR) KPSS

Null Hypothesis: LOUR is stationary

Exogenous: Constant, Linear Trend

Bandwidth: 4 (Newey-West using Bartlett kernel)

\begin{tabular}{|c|c|c|}
\hline & & LM-Stat. \\
\hline \multicolumn{2}{|c|}{ Kwiatkowski-Phillips-Schmidt-Shin test statistic } & 0.168335 \\
\hline \multirow[t]{3}{*}{ Asymptotic critical values*: } & $1 \%$ level & 0.216000 \\
\hline & $5 \%$ level & 0.146000 \\
\hline & $10 \%$ level & 0.119000 \\
\hline \multicolumn{3}{|c|}{ *Kwiatkowski-Phillips-Schmidt-Shin (1992, Table 1) } \\
\hline \multicolumn{2}{|c|}{ Residual variance (no correction) } & 0.011275 \\
\hline \multicolumn{2}{|c|}{ HAC corrected variance (Bartlett kernel) } & 0.023211 \\
\hline
\end{tabular}


Quadro 17 - Teste raiz unitária volume de crédito (LCRE) Phillips-Perron

Null Hypothesis: LCRE has a unit root

Exogenous: Constant, Linear Trend

Bandwidth: 4 (Newey-West using Bartlett kernel)

\begin{tabular}{lllc}
\hline & & Adj. t-Stat & Prob. ${ }^{*}$ \\
\hline Phillips-Perron test statistic & & -5.466486 & 0.0003 \\
\hline Test critical values: & $1 \%$ level & -4.205004 & \\
& $5 \%$ level & -3.526609 & \\
& $10 \%$ level & -3.194611 & \\
\hline${ }^{*}$ MacKinnon (1996) one-sided p-values. & & & \\
Residual variance (no correction) & & & 0.245314 \\
HAC corrected variance (Bartlett kernel) & & & 0.310530 \\
\hline
\end{tabular}

Quadro 18 - Teste raiz unitária volume de crédito (LCRE) KPSS

Null Hypothesis: LCRE is stationary

Exogenous: Constant, Linear Trend

Bandwidth: 4 (Newey-West using Bartlett kernel)

\begin{tabular}{lll}
\hline & & LM-Stat. \\
\hline Kwiatkowski-Phillips-Schmidt-Shin test statistic & & 0.094985 \\
\hline Asymptotic critical values*: & $1 \%$ level & 0.216000 \\
& $5 \%$ level & 0.146000 \\
& $10 \%$ level & 0.119000 \\
\hline *Kwiatkowski-Phillips-Schmidt-Shin (1992, Table 1) & & \\
Residual variance (no correction) & & 0.247167 \\
HAC corrected variance (Bartlett kernel) & 0.416784 \\
\hline
\end{tabular}




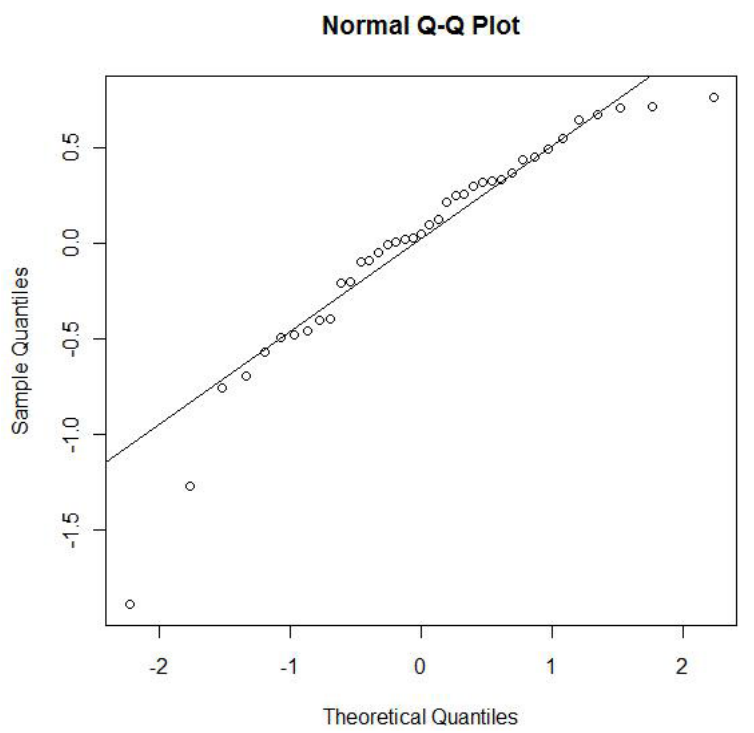

Imagem 1 - Análise Q-Q plot dos resíduos da Equação (1) 